\section{Talking of molecular stereodynamics}

\author{
Struther Arnott
}

Journal of Biomolecular Structure \& Dynamics. Editor-in-chief Ramaswamy H. Sarma. Adenine Press, PO Box 355, Guilderland, New York 12084, USA. 6/yr. $\$ 351$ (corporate), $\$ 240$ (institutional), $\$ 99$ (individual), $\$ 60$ (student).

Some think that the State University of New York at Albany is an academic backwater, another memorial in elegant concrete to the brave but abortive efforts of the late Governor Rockefeller to mimic in his state the economic magnetism of the University of California system. Yet Albany has become magnetic in an unexpected way as a Mecca for the legions of (mainly nucleic acid) physical biochemists who are the intellectual offspring or grandchildren of the philoprogenitive pioneers of what passed for molecular biology in the 1950)s and early 1960)s. There is now a biennial pilgrimage to the "Conversations in Biomolecular Stereodynamics", whose efficient and verveful impresario is Ramaswamy Sarma.

As is now too often the case, these Conversations begat published proceedings. Then, to the surprise of many contributors but the dismay of only a few, the proceedings of the Third Conversation were transmuted into the first four or five numbers of the Journal of Biomolecular Structure \& Dynamics.

Anyone who has had to swallow the sour draught of the patronizing reports Journal of

Biomolecular Structure \& Dynamics

from the Journal of Molecular Biology must welcome a new journal which not only permits you to nominate your own referees, but urges you to list scientists who should not be allowed to referee your paper. The price of such a liberal policy is all too evident: poor articles with the spurious authority of plenty of numbers and good graphics have come to rest here after unsuccessful attempts to dock in more discriminating journals; strident articles that are more offensively partisan than is common; and potentially good articles that have been permitted to be self-indulgently prolix. Some editors have exploited this licence no less than their other authors. But reforms may be imminent. As a start, we are told, the editor responsible for accepting a paper will in future be advertised.

The production of the journal is "high tech". Potential authors are invited to submit manuscripts on computer tapes or floppy discs or by electronic transmission. Laser optics are used to read ordinary manuscripts and to set type. In-house copy editing has been profitably aban- doned, and fastidiousness about English usage has been gaily abandoned. Nevertheless, successive numbers have been pleasant to read and look at, with ungrudging space for illustrations.

The popularity of the Conversations in Albany indicates that there is a gap for this journal to exploit. This interstitial niche is occupied by physical scientists on the fringes of biology who are concerned mainly with molecular structures. They have at their disposal increasingly powerful probes, such as nuclear magnetic resonance and X-ray diffraction, and tools such as computer graphics and even supercomputers. The preferred audience for their voluminous output is people like themselves, despite the obvious danger of intellectual incest through protection

\section{Resonating promise}

\section{David Gadian}

Magnetic Resonance in Medicine. Editorin-chief E. Raymond Andrew. Academic. 6/yr.UK $£ 68.50$, North America $\$ 85$ (for 1985).

Magnetic Resonance Imaging: An International Journal of Basic Research and Clinical Applications. Editors-in-chief John C. Gore and Francis W. Smith. Pergamon. 6/yr. UK £88 (institutional), £29 (individual); North America $\$ 150$ (institutional), $\$ 50$ (individual).

NUCLEAR magnetic resonance (NMR) is attracting considerable interest as a noninvasive method of obtaining images of the human body and of studying tissue metabolism. The related technique of electron paramagnetic resonance is also becoming increasingly used in biomedical research. Much of the work in this area is highly interdisciplinary, and established meetings and journals do not necessarily provide an appropriate forum for discussion or publication of research results; hence the emergence of two new societies and their associated journals.

Magnetic Resonance in Medicine, which is the official journal of the Society of Magnetic Resonance in Medicine, has taken the eminently sensible approach of adopting a similar format to the wellrespected and well-established Journal of Magnetic Resonance. The journal includes regular papers, together with shorter communications and notes, and many of the recent papers have appeared within eight to nine months of submission. As the official journal of a flourishing society, the journal should be assured of a fairly wide readership, and it should attract contributions from the many magnetic resonance specialists who are now involved in biomedical research.

Magnetic Resonance Imaging is also the official publication of a new society, the Society of Magnetic Resonance Imaging. from the proper darwinian pressures both from specialists in the technologies being used and from the biologists who should be defining the goals of this large investment in people and hardware.

Ironically the long-term scientific success of the Journal of Biomolecular Structure \& Dynamics may be ensured only by divergent evolution from the phenotype that ensured its successful birth. That this may be possible is demonstrated by a recent policy decision to de-parochialize the board of editors, currently dominated by nucleic acid interests. Such a step is necessary. I doubt if it will prove sufficient.

Struther Arnott is Vice President for Research and Dean of the Graduate School, Purdue University, West Lafayette, Indiana 47907 , USA.

Its emphasis differs somewhat from that of Magnetic Resonance in Medicine, in that rather more of the articles are clinically orientated, with many contributions coming from hospital research groups. Thus, as well as original scientific papers on physics, biology and medicine, clinical case reports are also published. In addition, an abstract service, book reviews, review articles and some invited articles are regular features. From time to time, the intention is to devote special numbers to areas of particular importance; for example a recent issue is concerned specifically with the use of contrast agents in magnetic resonance imaging.

In the short term. the success of these journals will depend on the number of high-quality papers that they attract, and in this respect they have taken steps in the right direction, with good editorial control and improving speed of publication. Further evidence of health is that both have progressed from quarterly to bimonthly publication. It might seem that the appearance of two new journals de-

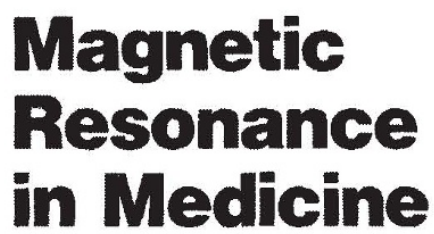

voted to this fairly specialized area is excessive. However, they do differ in their emphasis and approach, and if this distinction between them develops further then each should find its own niche. With regard to their long term prospects, magnetic resonance continues to advance in leaps and bounds forty years after the first successful NMR studies were performed, and there is every reason to believe that further developments will continue to justify the existence of these journals.

David Gadian is Director of Physics in Relation to Surgery at the Roval College of Surgeons of England, 35-43 Lincoln's Inn Fields, London $W C 2 A 3 P N, U K$ 